\title{
A linguistic analysis of user-generated book reviews: Truthful, deceiving or influential?
}

\author{
Lala Hajibayova \\ Kent State University, School of Information \\ lhajibay@kent.edu
}

\begin{abstract}
Keywords
User-generated reviews, Goodreads, computational linguistic analysis of user-generated reviews

\section{INTRODUCTION}

This study presents an analysis of 474,803 unique Goodreads reviews of the top-rated books in 2014. Studies of user-generated reviews have considered a range of issues, including analysis of what makes a review helpful (e.g., Otterbacher, 2011), such as evaluating helpfulness of reviews (e.g., Lee \& Koo, 2015) and evaluating linguistic characteristic of reviews (e.g., Aerts, Smits, \& Verkegh, 2017). For example, Mudambi and Schuff's (2010) analysis of Amazon.com reviews found that depth and product type affect the perceived helpfulness of a review, and reviews with extreme positive and negative ratings are considered less helpful than those with moderate ratings.
\end{abstract}

Goodreads, an Amazon-owned book-based social web site, has become a popular platform for readers and writers to connect with one another, read and post reviews, and carry on discussion of literary topics. Goodreads has 75 million members who have provided 70 million reviews of 2.2 million books (Goodreads, n.d.). Goodreads' reviews are considered a valuable resource for library acquisitions and reference services (Thelwall \& Kousha, 2017) and recognized by the major library cataloguing services, such as WorldCat. However, the practice of recommending Goodreads reviews raises a number of questions, such as how particular reviews are identified as relevant to users' searches and what criteria WorldCat algorithms utilize to suggest reviews and potentially influence individuals' reading choices (Hajibayova, 2017).

\section{METHODS}

Individuals' language has been long considered a valuable resource for gaining insight into their psychological characteristics (Boyd \& Pennebaker, 2017). Biber (1991, 1993), for example, observed significant differences among various types of texts, such as more frequent use of first person pronouns and present-tense verbs in the romance novels.

$81^{\text {st }}$ Annual Meeting of the Association for Information Science \& Technology | Vancouver, Canada | Nov. 10 - 14, 2018 Author(s) Retain Copyright
This study utilized the Linguistic Inquiry and Word Count (LIWC) computational linguistic application (Pennebaker, Boyd, Jordan, \& Blackburn, 2015; Pennebaker, 2011) to investigate how individuals' formal and informal written and spoken language reflect their psychological states (Pennebaker, Boyd, Jordan, \& Blackburn, 2015; Pennebaker, 2011).

For each given text LIWC analysis yields approximately 90 output variables, including word count, four summary language variables (analytical thinking, clout, authenticity, and emotional tone), three general descriptor categories (words per sentence, percent of target words captured by the dictionary, and percent of words in the text that are longer than six letters), 21 standard linguistic dimensions (such as percentage of words in the text that are pronouns, articles, auxiliary verbs), 41 word categories tapping psychological constructs (such as affect, cognition, biological processes, drives), six personal concern categories (such as work, home, leisure activities), five informal language markers (such as assents, fillers, swear words, netspeak), and 12 punctuation categories (such as periods, commas ). An LIWC Dictionary is composed of almost 6,400 words, word stems, and select emoticons. The LIWC application assigns each word into defined linguistic categories and provides the total number of words in each category in relation to the total number of words in the given text (Pennebaker, Boyd, Jordan, \& Blackburn, 2015).

\section{RESULTS AND DISCUSSION}

Analysis of 474,803 reviews revealed an average of 45 words per review $(M=45, S D=162.89)$.

Linguistic analysis of reviews revealed strong correlation between use of personal pronouns (.589), impersonal pronouns (.627), auxiliary verbs (.733), negations (.494), and some positive emotions (-.301). The high use of personal and impersonal pronouns, auxiliary verbs and negations reflect the overall extensive use of function words in the English language (Chung \& Pennebaker, 2007). However, the optimistic writings may suggest some form of deception (Pennebaker, 2011), which has been also reported in studies of online reviews (e.g., Zhou, Burgoon, Nunamaker, \& Twitchell, 2004). The relatively high use of function words coupled with a positive tone may also imply reviewers' intention to promote their review and influence one's reading choice.

The findings of this study suggest that a relatively high use of function words coupled with the predominantly positive 
tone of reviews can be interpreted as reviewers' attempt to influence one's reading choices. This study also suggests that transparency regarding inclusion of user-generated reviews in traditional systems of information representation and organization should be considered. In particular, inclusion of certain Goodreads reviews as relevant to users' searches in WorldCat should also include information on how/why utilized algorithms suggest certain reviews and potentially influence individuals' reading choices (Hajibayova, 2017).

\section{REFERENCES}

Aerts, G., Smits, T., \& Verlegh, P.W.J. (2017). How online consumer reviews are influenced by the language and valence of prior reviews: A construal level perspective. Computers in Human Behavior 75, 855-864.

Biber, D. (1991). Variations Across Speech and Writing. Cambridge, UK: Cambridge University Press.

Biber, D. (1993). Using register-diversified corpora for general language studies. Journal of Computational Linguistics 19(2), 219-241.

Boyd, R.L., \& Pennebaker, J.W. (2017). Language-based personality: A new approach to personality in a digital world. Current Opinion in Behavioral Sciences 18, 6368.

Chung, C., \& Pennebaker, J. (2007). The psychological functions of function words. In K. Fiedler (Ed.), Social Communication (pp. 343-360). New York, NY: Psychology Press.

Goodreads (n.d.). About Goodreads. Retrieved from https://www.goodreads.com/about/us?rel=nofollow

Hajibayova, L. (2017). An investigation of user-generated book reviews: Goodreads or Badreads? International Society for Knowledge Organization UK Biennial Conference. London, UK, 11-12 September, 2017
Otterbacher, J. (2011). Being heard in review communities: Communication tactics and review prominence. Journal of Computer-Mediate Communication 16(3), 424-444.

Lee, K.-T., \& Koo, D.-M. (2015). Evaluating right versus just evaluating online consumer reviews. Computers in Human Behavior 45, 316-327.

Mudambi, S.M., \& Schuff, D. (2010). What makes a helpful online review? A study of customer reviews on Amazon.com. MIS Quarterly 34(1), 185-200.

Pennebaker, J. (2011). The Secret Life of Pronouns: What Our Words Say About Us. New York, NY: Bloomsbury Press

Pennebaker, J.W., Boyd, R.L., Jordan, K., \& Blackburn, K. (2015). The development and psychometric properties of LIWC2015. Austin, TX: University of Texas at Austin.

Thelwall, M., \& Kousha, K. (2017). Goodreads: A social network site for book readers. Journal of the Association for Information Science \& Technology 68(4), 972-983.

Yoo, K.-H., \& Gretzel, U. (2009). Comparison of deceptive and truthful travel reviews. In W. Höpken, U. Gretzel, \& R. Law (Eds.), Proceedings of Sixteenth International Conference on Information and Communication Technologies in Travel and Tourism, Amsterdam, Netherlands, January 28-30, pp. 37-47. Amsterdam, Netherlands: Springer-Verlag/Wien.

Zhang, Z., \& Varadarajan, B. (2006). Utility scoring of product reviews. Proceedings of the $15^{\text {th }}$ ACM International Conference on Information and Knowledge Management, Arlington, Virginia, USA, November 6-11, 2006, pp. 51-57. New York, NY: ACM.

Zhou, L., Burgoon, J.K., Nunamaker, J.F., \& Twitchell, D. (2004). Automating linguistic-based cues for detecting deception in text-based asynchronous computer-mediated communication. Group Decision and Negotiation 13(1), 81-106. 